\title{
Reciclar Recordações com as Ciências Percursos de Aprendizagem em Contexto de Jardim de Infância
}

\author{
Maria Eduarda Roque Ferreira ${ }^{1}$ \\ Carla Cepa ${ }^{2}$ \\ Rosa Tracana ${ }^{3}$ \\ Carlos Francisco Reis ${ }^{4}$
}

\begin{abstract}
Resumo
Seguindo-se um modelo de formação de educadores de infância em que são privilegiadas práticas pedagógico-didáticas com uma orientação de cariz prático, analisam-se os resultados de uma investigação educacional, enquadrada na formação destes profissionais. A investigação seguiu uma abordagem qualitativa. Partiu-se do pressuposto de que a educação baseia-se em premissas sociais, culturais, individuais e coletivas, e neste contexto, desenvolveu-se, com um grupo de crianças que frequentam a educação pré-escolar, uma experiência pedagógico-didática a que intitulamos Reciclar Recordações - A Magia das Ciências. Esta foi enquadrada no trabalho de projeto, trabalhada numa perspetiva interdisciplinar em contexto de ensino das Ciências, operacionalizada por meio da realização de atividades práticas, tendo por enfoque a triangulação ciência-criança-meio sociocultural. Utilizaram-se as seguintes categorias de análise: metodologia de ensino e recursos didáticos construídos; conceções das crianças; articulação ciência-criança-meio sociocultural. Constatou-se que esta experiência pedagógico-didática permitiu desenvolver, nestas crianças, a autonomia, a partilha, o entusiasmo pela descoberta, o conhecimento científico, e possibilitou o reviver
\end{abstract}

$1 \mathrm{PhD}$ em Biologia pela Universidade de Aveiro, Portugal. Agregação em Educação pela Universidade da Beira Interior, Portugal. Professora Coordenadora Principal em Ciências da Educação na Escola Superior de Educação, Comunicação e Desporto do Instituto Politécnico da Guarda (IPG).eroque@ipg.pt

2 Instituto Politécnico da Guarda (IPG). carlacepa@gmail.com

3 Unidade de Investigação para o Desenvolvimento do Interior (UDI), Instituto Politécnico da Guarda (IPG). rtracana@ipg.pt

${ }^{4}$ Centro de Estudos Interdisciplinares do Século XX da Universidade de Coimbra-CEIS20; Unidade de Investigação para o Desenvolvimento do Interior (UDI), Instituto Politécnico da Guarda (IPG).csreis@uc.pt 
do passado, trazendo-o para o presente, como por magia. Reciclar as memórias dos seus antepassados e recordar a alegria das coisas simples, em testemunhos plenos de sinceridade, são um contributo valioso para a ligação intergeracional e a preservação da memória coletiva.

Palavras-chave: Trabalho de projeto. Atividades práticas em ciências. Formação do educador de infância.

\title{
RECICLING MEMORIES WITH SCIENCE - LEARNING PATHWAYS IN KINDERGADEN
}

\begin{abstract}
We have carried out an educational study following the model of Kindergarten Teachers' Education in Portugal, while privileging pedagogical-didactic practices with practical oriented guidance. The research was undertaken as a qualitative approach, supported by the assumption that education is based on social, cultural, individual and collective premises. We developed the research based on a group of children attending pre-school education, by applying an experience entitled "Recovering Memories Through Magic Sciences". Such dynamic was inserted in a work project, developed within an interdisciplinary perspective aimed to science education, which was operationalized by conducting practical activities focused in triangulating science-child and sociocultural context. In order to analyse the results we applied the following categories: teaching methodologies and didactical resources; children conceptions; science-child and sociocultural context articulation. We found that this pedagogical and didactic experience has foster autonomy, the recovering of past explorations and the understanding of scientific knowledge, while recovering our tradition for dealing with everyday issues, "as if by magic". In order to retrieve the memories of our common experience - thus recovering the joy of meaningful simple things - we have tried to produce a contribution for enriching intergenerational entanglement of our collective memory.
\end{abstract}

Keywords: Science education. Teaching methodologies. Didactical resources. Recovering memories. 
A educação pré-escolar, a primeira etapa da educação básica em Portugal, tem por finalidade proporcionar um desenvolvimento harmonioso, favorecendo a formação e o desenvolvimento equilibrado da criança, tendo em vista a sua plena inserção na sociedade como ser autônomo, livre e solidário (MINISTÉRIO..., 2007, p. 15), considerado como a estrutura de suporte da educação que se irá consolidar ao longo da vida. Segundo Formosinho (2013), em Portugal tem vindo a desenvolver-se a consciência, cada vez mais, da importância da educação pré-escolar para o sucesso escolar e pessoal das crianças e para a própria melhoria do sistema educativo (p. 11), pensou-se que a educação das crianças pequenas devia ser diferente da educação das crianças mais velhas e dos jovens (Ibidem, p. 14). O conceito de educação e a concepção de criança evoluiu ao longo dos tempos, de acordo com as realidades socioculturais e econômicas. Atualmente a investigação em Didática das Ciências preconiza uma educação voltada para a criança, em que esta experimente, manipule e aprenda a fazer, sendo considerada o centro do processo de ensino e aprendizagem. Os primeiros anos de vida são determinantes para o desenvolvimento da criança, um processo biopsicossocial e cultural de desenvolvimento (COLE, 1999, p. 129), competindo ao educador fomentar metodologias e estratégias de ensino adaptadas aos contextos, às necessidades e ritmos de desenvolvimento de cada criança. Segundo Kant (1985), o homem não se pode tornar homem a não ser pela educação. Ele não é senão o que a educação faz dele (p. 75).

É preconizado para a educação pré-escolar um processo de ensino e aprendizagem diversificado, tirando melhor partido de recursos e de condições, de forma a incrementar o desenvolvimento cognitivo, social e emotivo das crianças (PEREIRA, 2002, p. 75), proporcionando-se experiências variadas e motivadoras, com vista a estimular e a ajudar a criança a encontrar-se e a integrar-se na cultura e na sociedade em que vive, preferencialmente em contextos de experienciação. Assim, segundo as orientações curriculares da educação pré-escolar de Portugal (MINISTÉRIO..., 2007), o educador deve contemplar a organização do ambiente educativo, as áreas de conteúdo, as suas intencionalidades educativas, nomeadamente o observar, planear, agir, avaliar, comunicar e articular (p. 14). Neste contexto, há que valorizar o ensino das Ciências de cariz prático, uma vez que proporciona a aquisição de conhecimentos e o 
desenvolvimento do pensamento crítico (MARTINS; VEIGA, 1999; SÁ 2002; PEREIRA, 2002; CONSELHO..., 1999; REIS, 2009; FERREIRA; PORTEIRO; PITARMA, 2015; COSTA et al., 2014). Na perspetiva de Carvalho e Diogo (1994), os temas abordados devem ter relevância social e cultural, contudo as atividades que o professor seleciona devem ter significado para as crianças e envolvê-las no seu todo, embora cada criança as "trabalhe" de modo diferente, atendendo aos seus interesses, capacidades e conhecimentos (PEREIRA, 2002, p. 19). De acordo com Carvalho et al. (1993),

não se trata de ensinar um mero corpo de conhecimentos técnicos, mesmo que irrepreensivelmente actualizado. Trata-se antes, sobretudo, de preparar cada um (e todos) para ser protagonista do seu itinerário individual e social a desenvolver, bem entendido, de acordo com os conhecimentos disponíveis, mas igualmente no âmbito de uma óptica prefigurativa do tempo em que a antecipação operatória do futuro, delineada pelo(s) projecto(s), procura assegurar a construção de um devir humanamente consequente (p. 14-15).

Na educação pré-escolar as aprendizagens das Ciências têm como objetivo dar sentido ao meio que rodeia a criança (POZO; GOMEZ CRESPO, 2001). A criança desenvolve competências de modo próprio e a aquisição de conhecimentos concetuais e procedimentais processam-se em diversos contextos, nomeadamente por meio da brincadeira, na qual estrutura a sua curiosidade e o desejo de saber mais sobre o mundo que a rodeia.

O ensino das Ciências, na educação pré-escolar em Portugal, encontra-se preconizado na área curricular do "Conhecimento do Mundo", tendo como objetivo a iniciação/sensibilização para os diversos conteúdos no âmbito da Geografia, da Física, da Química e da Biologia. Esta área visa a despertar, na criança, a curiosidade e o desejo de aprender sobre o mundo que a rodeia (MINISTÉRIO..., 2007), promovendo assim o seu desenvolvimento harmonioso, em temas transversais e integrados no meio envolvente. 
Do educador espera-se competências no ensino das Ciências que lhes permitam formar cidadãos intervenientes e ativos. O contato com a ciência pode contribuir para o desenvolvimento e a maturação das capacidades intelectuais da criança, vai forjando hábitos de observação cuidadosa, de utilização da linguagem com propósitos descritivos (PEREIRA, 2002, p. 35).

De acordo com Sá (2002), a ciência pode ajudar as crianças a pensarem logicamente sobre o dia a dia e a resolver problemas práticos simples. Tais competências intelectuais serão úteis para elas onde quer que vivam e independentemente da profissão que vierem a ter; - o ensino das Ciências promove o desenvolvimento cognitivo (p. 32). Segundo Martins et al. (2007), a educação em Ciências deve ser encarada, primeiramente, como promotora da literacia científica (p. 19).

A aprendizagem das Ciências não pode ser caraterizada por uma visão segmentada entre a apreensão de conteúdos e de processos, mas pela interação dinâmica que possibilita às crianças mobilizar os seus saberes concetuais e processuais no desenvolvimento de processos investigativos para, deste modo, construírem e reconstruírem contínua e progressivamente a sua compreensão do mundo, uma vez que este pode oferecer um manancial de fatos e experiências com um forte componente lúdico (SÁ, 2000, p. 3).

O ensino das Ciências dever partir da triangulação ciência-indivíduo-sociedade (PEREIRA, 1992). Neste contexto a construção do conhecimento depende do aluno, ele próprio gera a sua aprendizagem (CACHAPUZ; PRAIA; JORGE, 2002, p. 166), ou seja, os alunos constroem espontaneamente ideias - antes, durante e depois do ensino formal - podendo colidir com explicações de momento aceites (SANTOS et al., 1997, p. 146), com particular destaque para ideias transportadas para a sala de aula e dizendo respeito a explicações de fenómenos do mundo natural (CACHAPUZ, 1993, p. 48), na medida em que aprender pressupõe um processo pessoal e ativo de construção de conhecimento (MARTINS; VEIGA, 1999, p. 5).

Pereira (1992) salienta que a ciência, para além do edifício de conceitos, princípios e teorias que a caracterizam e individualizam, possui também um conjunto de modos de ação e pensamento designados por processos da ciência 
(p. 34); assim as crianças adquirem instrumentos de pensamento capazes de as ajudar a progredir, globalmente, por meio do aprender a aprender. Neste âmbito, a aprendizagem é pois o processo de construção que inclui conflitos, integrações e sobretudo interferências que resultam das interações necessárias entre concepções e conceitos e sobretudo entre os múltiplos elementos que constituem as concepções (...) (SANTOS et al., 1997, p. 167). É, portanto, relevante desenvolver uma intencionalidade no desencadear de situações didáticas capazes de potenciar uma aprendizagem significativa.

O ensino das Ciências, na educação pré-escolar, não deve ser abordado de forma isolada, mas com caráter interdisciplinar, baseado num modelo holístico e motivador, pois quando a criança revela um interesse natural na realização da tarefa, o esforço surge espontaneamente, sem necessidade de coação do professor (MARQUES, 2001, p. 108), devendo então o professor explorar o interesse natural da criança para os fins educativos. Neste sentido a criança tem assim a percepção de que algo é verdadeiro mas não tem palavras nem esquemas mentais que lhe permitam explicar (ALMEIDA; VILELA, 1996, p. 21), devendo o educador partir das conceções das crianças.

Na perspectiva de Cachapuz (2009), "um possível ponto de partida para motivar os alunos é estabelecer a relação do que se ensina" (conteúdos), com $o$ para que se ensina (finalidades) e para quem se ensina (destinatários), de forma a poder desenvolver aprendizagens profícuas.

O ensino experimental é caracterizado pelo propósito de levar a criança a aprender por meio de observações, discussões e experimentações, cujos resultados são interpretados e comparados (MARCOZZI; DORNELLES; REGO, 1980, p. 227), sendo evocado desde long a data como inerente, essencial, imprescindivel no ensino das Ciências (CONSELHO..., 1999, p. 23). Assim sendo, as atividades experimentais são conduzidas de modo a que as crianças observem, questionem, experimentem, verifiquem e decidam (REIS, 2009, p. 9), de modo a fomentar a curiosidade e o seu raciocínio, de uma forma lúdico-didática. Estas atividades quando realizadas de forma integrada, no âmbito de um trabalho de projeto, podem conduzir a aprendizagens nas diferentes áreas e domínios constantes das orientações curriculares da educação pré-escolar de Portugal. 
Segundo Vasconcelos (2011),

\begin{abstract}
o trabalho de projecto contribui para que as aprendizagens tenham um significado, sejam portadoras de sentido, envolvendo as crianças (ou os adultos) na resolução de problemas reais ou na busca de respostas desconhecidas. Tal processo de aprendizagem permite o desenvolvimento de competências essenciais numa sociedade de conhecimento: a recolha e o tratamento de informação e, simultaneamente a aprendizagem do trabalho de grupo, da colaboração, da tomada de decisão negociada, a atividade meta-cognitiva, e o espírito de iniciativa e criatividade (p. 9).
\end{abstract}

Na perspetiva de Mateus (2011), o trabalho de projeto é uma metodologia investigativa centrada na resolução de problemas reais e pertinentes, que permite criar uma nova relação entre a prática e a teoria, entre os saberes escolares e os saberes sociais (p. 3). Por seu lado Santos, Leite e Malpique (2008) referem que o trabalho por Projeto é uma atividade intencional pela qual o ator social, tornando o problema que o interessa, produz conhecimentos, adquire capacidades, revê elou adquire atitudes elou resolve problemas que o preocupam mediante o estudo e envolvimento numa questão autêntica ou simulada da vida real (p. 89).

A pedagogia de projeto surge como oposição à pedagogia tradicional, inserindo-se na escola nova. Um projeto é uma experiência que não se pode prever com uma certeza absoluta. Emerge e desenvolve-se na interação de um grupo particular de crianças e adultos, originando uma dinâmica única (FORMOSINHO, 2013, p. 126). Este é caraterizado como um campo de tensões e contradições mas, simultaneamente, como um sistema aberto, que permite proporcionar pontos de crescimento no trabalho articulado entre disciplinas, promotor de um novo conhecimento que é, necessariamente, transdisciplinar (VASCONCELOS, 2011b, p. 21). De acordo com Pereira (1992), o trabalho de projeto utiliza-se visando a explorar um tópico em profundidade, por exemplo, (...) situar o assunto de acordo com a perspectiva histórica e de relação com a sociedade (p. 187). 
O desenvolvimento de trabalho de projeto interliga um conjunto de conhecimentos nas diferentes áreas do saber (interdisciplinaridade) partindo do conhecido para a descoberta, do próximo para o afastado, do elementar para o complexo, ou seja, a promoção de múltiplas situações que inevitavelmente são responsáveis pelo "crescimento" cognitivo dos alunos (ALMEIDA; VILELA, 1996, p. 10). Katz e Chard (1997) consideram que a abordagem de projeto pode compreender uma vasta gama de tópicos que são relevantes localmente e culturalmente adequados aos participantes (...) e características que sejam únicas no seu ambiente (p. 265). Na perspetiva de Barbier (1996) o projeto não é uma simples representação do futuro, do amanhã, do possível, de uma "ideia", é o futuro "a fazer", um amanhã a concretizar, um possível a transformar em real, uma ideia a transformar em ato (p. 52). Segundo Bento (2007), a educação é um processo holístico e sinérgico, um processo cujo resultado não é a simples acumulação, ou soma de experiências educativas distintas que o sujeito vive, mas uma combinação muito mais complexa em que tais experiências se influenciam mutuamente (p. 30). Mendonça (2002) enfatiza a relevância da observação da criança como um ser competente, a quem deve ser dada oportunidade de ser cada vez mais autônoma e capaz de gerir o seu próprio processo de aprendizagem.

No entendimento de Costa (1991), o projeto educativo é o instrumento organizacional de expressão da vontade colectiva desta escola-comunidadeeducativa, é um documento que dá um sentido útil à participação, é a corporização operativa da autonomia da escola (p. 5), tem um caráter pedagógico, é elaborado com a participação da comunidade educativa e deverá ser trabalhado ao longo do ano letivo. De acordo com Hohmann, (1997),

o desenvolvimento curricular é um processo que requer compromisso com uma filosofia educativa abrangente e bem definida; um conhecimento extenso acerca do crescimento e do desenvolvimento humano; uma experiência prática com crianças e a compreensão dos seus interesses; e uma capacidade de consolidar e interpretar um corpo de dados de investigação sempre crescente nas áreas de ensino e aprendizagem (p. 1). 
Utilizando como recurso didático as atividades práticas no ensino das Ciências - A Magia das Ciências - e tendo como intuito sensibilizar as crianças para o valor do passado cultural partiu-se, nesta investigação, para o Reciclar Recordações. $O$ ato de recordar envolve várias habilidades cognitivas, desde aquelas que permitem lembrar um fato pessoal, como o caminho de casa ao trabalho, até aquelas necessárias para escrever um livro contando a história de uma vida (GAUER; GOMES, 2008, p. 507). A facilidade e a vivacidade de recordar permitem fomentar relações entre memória, consciência, emoção, o reviver e o viajar até o passado, fomentando a imaginação. Segundo os mesmos autores, a recordação é também uma avaliação do que se está lembrando e do ato de lembrar em si, por meio de uma série de julgamentos, que variam do pré-reflexivo ao reflexivo (Idem, p. 508).

O trabalho de projeto com crianças constitui uma metodologia muito utilizada, sendo esta vista como uma investigadora nata. Na perspectiva de Katz e Chard (1997), no trabalho de projeto, o papel do professor é mais o de conselheiro e orientador do que o de instrutor (p. 171) e Williams, Rockwell e Sherwood (2003) acrescentam que o seu papel consiste em criar uma atmosfera na sala de aula que estimule a criatividade e a independência no seio de um ambiente seguro e bem vigiado (p. 27).

Neste sentido a criança não é um "cientista solitário", mas um "explorador", um investigador, um criador ativo de saberes em alternativa a ser um passivo receptor de saberes dos outros (VASCONCELOS, 2011a, p. 9). Esta metodologia está relacionada com uma visão interdisciplinar e transdisciplinar do saber. A necessidade de um plano de ação tem como objetivo uma antevisão, um momento de reflexão em grupo, mas este plano será flexível, sujeito a reajustamentos de conteúdos, de metodologias (MATEUS, 2011, p. 5).

Considerando todo o referencial teórico apresentado e a investigação que temos desenvolvido, no âmbito da formação de educadores de infância, enquadrada na Prática de Ensino Supervisionada (PES) do Mestrado em Educação Pré-Escolar e ensino do $1^{\circ}$ ciclo do ensino básico (confere formação em educador de infância e professor do ensino primário), orientou esta investigação educacional, em contexto da educação pré-escolar, a análise dos resultados 
decorrentes da instituição de uma proposta pedagógico-didática, alicerçada no trabalho de projeto, como metodoloia de ensino das Ciências, tendo por enfoque a triangulação ciência-criança-meio sociocultural.

\section{Considerações Metodológicas}

Esta investigação seguiu a abordagem qualitativa, pois esta metodologia permite uma interação constante de aproximação da teoria à prática, orientando a ação para a resolução de problemas decorrentes do processo de ensino e aprendizagem. Estando neste estudo envolvida a formação de uma aluna do Mestrado, em contexto da educação pré-escolar, esta metodologia de investigação torna-se uma mais-valia, pois permite desenvolver a função crítica na formação, as capacidades de observação e análise crítica, orientando a ação educativa para a resolução de problemas.

Considerou-se como ponto de partida o projeto educativo "Reciclar Recordações" do jardim de infância, onde iria ocorrer o estágio da prática de ensino supervisionada. $\mathrm{O}$ estudo desenvolvido teve por base uma intervenção pedagógico-didática, enquadrada no ensino das Ciências, e utilizando a metodologia de trabalho de projeto alicerçado na experienciação, operacionalizada por meio da realização de atividades práticas. Intitulou-se este trabalho de projeto: "Reciclar Recordações: A Magia das Ciências".

Pretendeu-se, pois, proporcionar conhecimentos científicos e, em simultâneo, desenvolver capacidades, atitudes e afetos em relação ao patrimônio cultural da criança no âmbito da área curricular do "Conhecimento do Mundo". Seguiu-se uma perspetiva de interdisciplinaridade com as seguintes áreas curriculares: "Conhecimento do Mundo", "Formação Pessoal e Social", "Linguagem Oral e Abordagem à Escrita" e "Expressão e Comunicação". Todas elas são áreas do conhecimento constantes nas orientações curriculares para a educação pré-escolar em Portugal (MINISTÉRIO..., 2007).

Reconhecendo-se o quanto é essencial para o sucesso das aprendizagens uma adequada exploração didática, construímos roteiros/percursos de ensino e aprendizagem para as atividades práticas desenvolvidas. Procuramos informa- 
ção sobre aspectos culturais, históricos e sociais do meio a que estas crianças pertenciam e que procuramos integrar nos objetivos deste trabalho de projeto. Nas regiões do interior de Portugal era tradição fabricar o sabão, fazendo-se a reutilização de resíduos do azeite (produto endógeno). Produzia-se sabão por meio da reação promovida pelo calor vindo da combustão da lenha, utilizando ainda como reagentes a cinza da lareira e flores. À época, era, igualmente, um valor patrimonial das regiões/famílias a preservação dos registros em papel, nomeadamente as fotografias da família. Partindo deste conjunto de pressupostos foram concebidos, validados e executados roteiros/percursos de aprendizagem. Neste enquadramento, a problemática de investigação definida foi: compreender se o trabalho de projeto, mediante a realização de atividades práticas, repercute no desenvolvimento de valores de preservação do patrimônio sociocultural do meio a que estas crianças pertencem.

Pelo que o nosso estudo procurou dar resposta às seguintes questões:

a) De que modo o projeto educativo do jardim de infância constitui contexto para o trabalho de projeto em Ciências?

b) Ocorrerão aprendizagens no âmbito da área curricular "Conhecimento do Mundo", por meio da realização de atividades práticas?

c) As aprendizagens no âmbito da área curricular "Conhecimento do Mundo" promovem o desenvolvimento de valores de preservação do patrimônio cultural?

Definiram-se, em consequência, como objetivos do estudo, os seguintes:

1) Construir e validar roteiros/percursos de aprendizagem em que a exploração didática se operacionaliza por intermédio de atividades práticas.

2) Constatar o contributo das aprendizagens pelas atividades práticas para o desenvolvimento de valores de preservação do patrimônio cultural.

Este trabalho de projeto foi desenvolvido, durante dois meses, no decorrer da PES, ao nível de educação pré-escolar. Esta PES desenvolve-se durante seis meses. 
Esta investigação teve como participantes quatro investigadores, um deles uma aluna do Mestrado de Educação. A intervenção educativa teve a participação ativa de um grupo de 16 crianças ( 7 meninas e 9 meninos), com idades compreendidas entre os 4 e os 6 anos de idade, que frequentava um jardim de infância de uma cidade do interior de Portugal. Eram crianças participativas e sociáveis. Esta instituição pertence à rede pública de jardins de infância que têm protocolo de colaboração com a instituição de Ensino Superior, da mesma cidade, para a realização da PES, ${ }^{5}$ integrada no anteriormente já referido.

No nosso estudo seguimos as seguintes fases em articulação/envolvimento com as crianças: definição das questões/problemas a descobrir, planejamento e execução, desenvolvimento, conclusão/sistematização.

Os recursos utilizados para recolher os resultados foram: observação direta, registr iconográficos (feitos pelas crianças), fotografias e registros escritos das concepções das crianças.

\section{Sequência do Desenvolvimento do Projeto}

O trabalho de projeto desenvolvido foi organizado numa sequência de cinco fases e cuja descrição encontra-se a seguir.

As atividades desenvolvidas pretendiam fomentar aprendizagens ao nível de conhecimentos (termos e conceitos do âmbito do conhecimento do mundo e conhecimentos interdisciplinares), capacidades (observar, classificar, descrever, prever, registar, interpretar, avaliar), atitudes e afetos (responsabilidade, envolvimento, iniciativa curiosidade, criatividade, alegria).

I) Por meio do diálogo enquadrado segundo o esquema a seguir (Figura 1).

5 Prática de Ensino Supervisionada. 
Figura 1 - Situação contextualizadora do trabalho de projeto

\section{O que queremos descobrir?}

\section{Reci̊cam Recordaçoొes}

Fonte: Os autores.

O grupo de crianças concorda que quer investigar: a) como se pode transformar o papel para ficar igual ao que os avós têm guardado no baú; b) como os nossos antepassados faziam o sabonete?

No nosso estudo, para cada atividade prática fez-se a construção de recursos e materiais didáticos seguindo-se na exploração didática as seguintes fases sequenciais:

II) Exploração e registro das concepções prévias das crianças (Figura 2).

Figura 2 - Parte inicial dos roteiros/percursos de aprendizagem onde as crianças assinalam as suas concepções

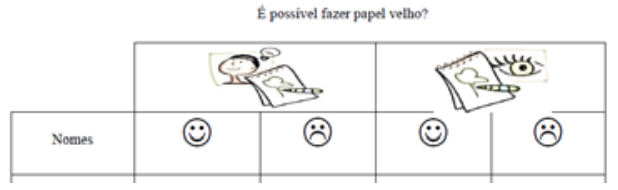

(a)

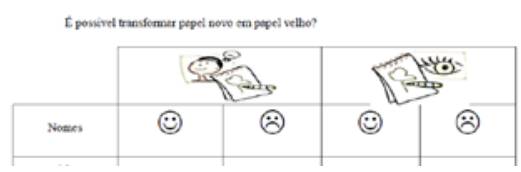

(b)

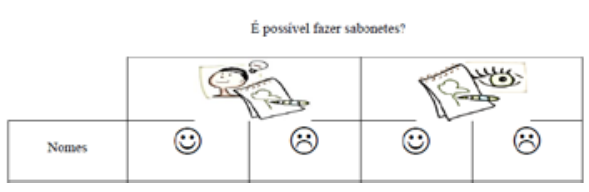

(c)

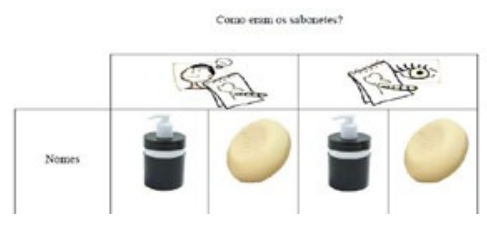

(d)

Legenda $:)_{\text {sim }} \quad \dot{\theta}_{\text {Nảo }}$

Fonte: Os autores. 
Após o diálogo sobre as questões-problema de cada roteiro/percurso de ensino e aprendizagem referente às atividades práticas as crianças assinalam com "X" a sua concepção.

III) Planejar e executar a experiência tendo por base a teia construída com as concepções prévias, da qual resultará a forma/metodologia de execução da atividade.

Seguimos a seguinte ordem de exploração das atividades práticas: primeiro trabalharam-se as atividades referentes ao papel e só depois as referentes ao sabonete.

IV) Confronto entre as concepções prévias e os resultados obtidos concluir.

\section{Análise dos resultados}

Neste estudo considerou-se para a análise dos resultados obtidos as seguintes categorias: metodologia de ensino e recursos didáticos; concepções das crianças; articulação ciência-criança-meio sociocultural. Por opção fazemos a análise dos resultados triangulando as três categorias de análise.

No Quadro 1 pode-se observar as concepções das crianças referentes às diferentes questões-problema constantes nos roteiros/percursos de ensino $\mathrm{e}$ aprendizagem das atividades práticas desenvolvidas. 
Nesta fase do desenvolvimento do projeto coincidiu o evento "Dia Nacional do Pijama”, intervenção pedagógica com a intenção de reforçar a relação escola-família. Neste contexto, integramos essa atividade na intervenção pedagógico-didática que se estava desenvolvendo, e fez-se a leitura do livro O Segredo dos Sabonetes (MUNDOS DE VIDA, 2013), explorando uma fotografia antiga, a preto e branco, da avó Mimosa, dando assim seguimento e enquadramento às atividades já previstas (Quadro 2). Com o grupo de crianças analisou-se os ingredientes/materiais que os antepassados usavam para fazer os seus sabonetes. Concluíram que os seus antepassados não tinham micro-ondas nem fogão a gás, por isso usavam o fogo da lareira na confecção dos seus alimentos e também para fazer o sabonete.

Quadro 2 - A exploração das atividades práticas

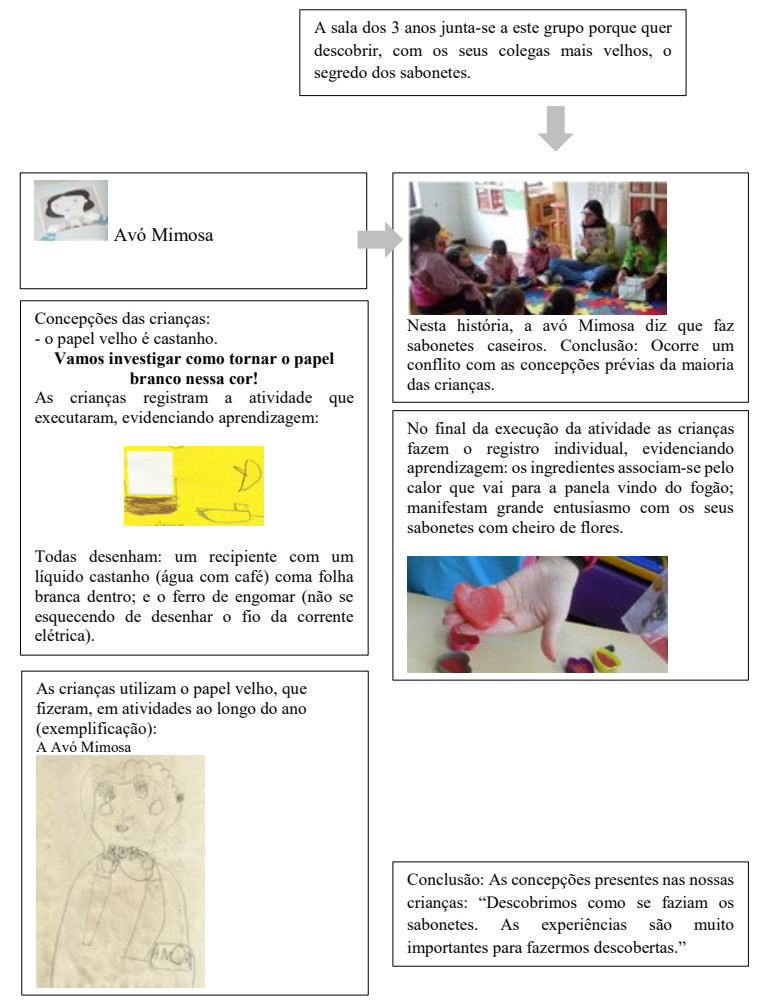

Fonte: Os autores. 
Constatou-se o entusiasmo destas crianças, quando no dia seguinte traziam retratos antigos dos seus antepassados e construíam com o papel velho a sua árvore genealógica para mostrá-la a todo o grupo, com grande alegria e entusiasmo (Figura 3).

Figura 3 - A árvore genealógica de todas as crianças do grupo

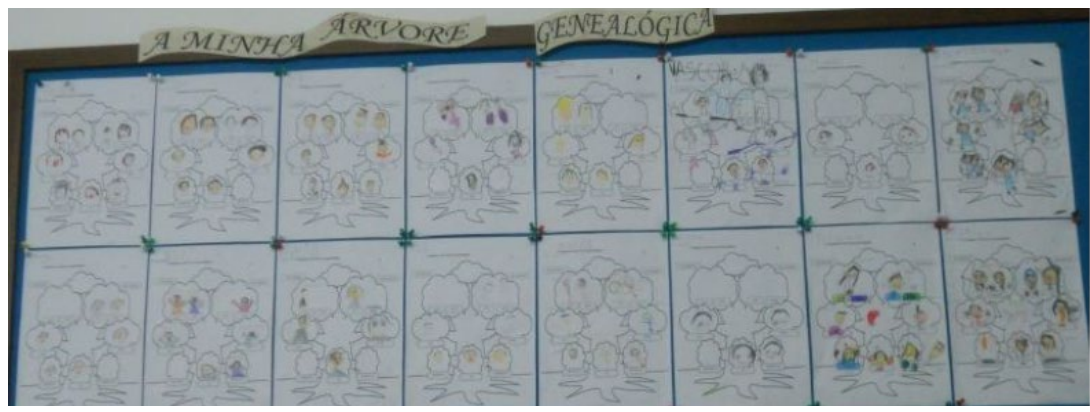

Fonte: Os autores.

Todas as crianças concluem que "o papel velho, que era dos nossos antepassados, deve ser guardado pois faz parte da nossa família”.

$\mathrm{Na}$ consolidação das aprendizagens a interdisciplinaridade atendeu à triangulação ciência-criança-meio sociocultural (Figura 4) e, em simultâneo, fez-se o reforço dos laços afetivos, tendo-se para tal construído, com as crianças, o seguinte poema, que todas recitaram acompanhando a aluna de PES:

"Fiz um sabonete;/Cheira tão bem;/Fiz sabonetes;/Para a minha mãe. Cheira cheira;/Cheira muito bem;/Cheira a carinho;/E a amor também. Pétalas de rosa;/Água e sabão;/Juntei uns corantes;/Fiz um coração. Cheira cheira;/Cheira muito bem;/É o sabonete;/Para a minha mãe."

Este poema acompanhou o sabonete, que cada criança fez, e constituiu o presente de Natal para a sua mãe.

Observou-se, no grupo, uma forte motivação e entusiasmo pela experienciação, fatores essenciais para a aprendizagem. $\mathrm{O}$ envolvimento da criança nas atividades desenvolvidas varia em razão de diversos fatores, individuais e de contexto, ligados à motivação (LOURENÇO; PAIVA, 2010). As apren- 
dizagens das Ciências devem dar significado ao meio com o qual a criança interage (POZO; GOMEZ CRESPO, 2001) e as práticas educativas deverão ser facilitadoras da educação em ciências (ESHACH 2006; MARTINS et al., 2009; FERREIRA; PORTEIRO; PITARMA, 2015; FERREIRA et al., 2016). Os roteiros/percursos de ensino e aprendizagem construídos, tendo por enfoque a triangulação ciência-criança-meio sociocultural, revelaram-se adequados às aprendizagens pretendidas e propiciadoras de entusiasmo pela descoberta. Segundo Pereira (2002), a forma como a atividade é colocada à criança, a maneira como o professor vai acompanhando e apoiando a criança, o que o professor vai dizendo, são questões fundamentais para que as atividades levem ao desenvolvimento das crianças, quer em termos cognitivos, quer em termos emocionais e atitudinais (p. 80). Os registros efetuados pelas crianças foram cruciais para o conhecimento das concepções prévias e posterior confronto com a observação dos resultados. Na verdade, colocou exigências ao pensamento e raciocínio destas, pois não há atividade científica sem registros, sem representações... esquemáticas e gráficas diversas (Idem, p. 101), desenvolvendo-se assim capacidades comunicativas. Nesta faixa etária, da educação pré-escolar, o registro icnográfico constitui um método que se revela adequado para a representação do que a criança imagina/vê/observa, de forma a exprimir os seus sentimentos, emoções e conhecimentos.

O diálogo permanente constituiu estratégia relevante, pois proporcionou às crianças a oportunidade de utilização da própria linguagem na construção de novos conhecimentos, uma vez que o ensino experimental das Ciências a crianças é tão importante na produção de evidências experimentais quanto a discussão sobre elas, o que, promovendo a aprendizagem em Ciências constitui, simultaneamente, um vigoroso processo de desenvolvimento de competências comunicativas (SÁ; VARELA, 2007, p. 12). Nesta perspectiva torna-se fundamental que a criança possa discutir com as outras crianças e com o professor que significados acorda ao que vê e experimenta. Trata-se de usar as actividades para pensar, ou seja, para serem usadas como contextos de minds-on (PEREIRA, 2002, p. 85), fomentando deste modo um hiato entre hands-on e minds-on, imprescindível ao desenvolvimento integral dos educandos. Assim, 
foi construída, com todo o grupo, no placar da sala de atividades, uma teia de sistematização de conhecimentos sobre o segredo dos sabonetes, constituindo em simultâneo um meio de divulgação/observação do trabalho desenvolvido.

Na Figura 4 visualiza-se, em teia conceptual, o trabalho de projeto que se desenvolveu com este grupo de crianças.

Figura 4 - Teia referente ao trabalho de projeto desenvolvido

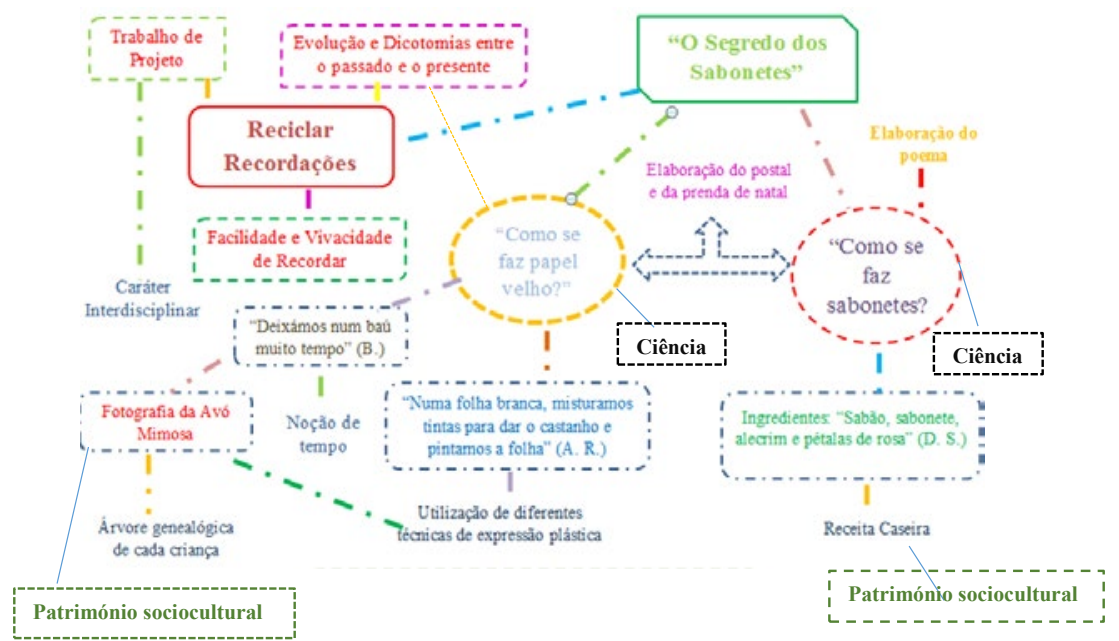

Fonte: Os autores.

Corrobora-se, tendo por base os resultados obtidos com a instituição desta proposta pedagógico-didática alicerçada no trabalho de projeto (Figura 4), o preconizado por Almeida e Vilela (1996), Katz e Chard (1997), Vasconcelos (2011b), Mateus (2011) e William, Rockwell e Sherwood (2003). As aprendizagens no contexto de descoberta, proporcionada pelo recurso às atividades práticas, revestiu-se de carácter mágico para este grupo de crianças que frequentam a educação pré-escolar. As atividades práticas, no ensino das Ciências numa visão interdisciplinar do saber, além de proporcionarem desenvolvimento cognitivo, possibilitaram o reviver do passado, trazendo-o para o presente, como por magia. Reciclar as memórias dos seus antepassados e recordar a alegria das coisas simples, em testemunhos plenos de sinceridade, são um contributo valioso para o desenvolvimento afetivo e para a ligação intergeracional. 
Carvalho e Diogo (1994) salientam que

as transformações sociais exigem de cada indivíduo uma cada vez maior especialização e parcelarização de saberes; paradoxalmente, para conduzir os acontecimentos - e não ser apenas conduzido - é necessário uma interpretação holística do mundo e uma cada vez maior intervenção de sentido globalizante, propondo a organização da acção numa conduta estratégica, conduzida pela intencionalidade e dominada pela capacidade de prever e antecipar (p. 8),

competindo, então, aos educadores, ter um olhar atento sobre essas mudanças, um renovar das estratégias, metodologias e pedagogias a desenvolver.

\section{Considerações Finais}

Neste trabalho de projeto apurou-se que a metodologia de abordagem escolhida e a sua operacionalização (atividades práticas) proporcionaram às crianças a oportunidade de aprender Ciências por meio do vivenciar, do experienciar, do descobrir, aproximou-as do conhecimento científico num contexto de aproximação as suas raízes socioculturais, permitindo-lhes construir o sentido de preservação desse seu patrimônio. Há a convicção de que doravante estas crianças estarão mais atentas ao patrimônio sociocultural da sua família/meio, questionando-se e procurando respostas para a preservação deste patrimônio, de forma criativa.

A análise dos registros e das respostas dadas mediante o diálogo evidenciou o interesse e a motivação das crianças, bem patente pelo entusiasmo em participar pelas crianças mais novas da outra sala, além do empenho de todas, revelado na tentativa de dar solução às questões-problema propostos, na manifestação de autonomia e respeito pelas regras.

Há, porém, a considerar, que as condições tidas para a realização deste trabalho de projeto podem, porventura, constituir fatores impeditivos para a sua replicação. Nomeadamente: não existência de limitação temporal; crianças assíduas; recursos materiais disponíveis. 
Reforçando-se a referência aos aspectos positivos deste estudo, estando presente a sua intencionalidade, constatou-se que a abordagem pedagógico-didática seguida, assente na interdisciplinaridade curricular, na experienciação e em questões-problema vindos do meio cultural próximo, potenciou: a curiosidade, o desejo de aprender (capacidades), a cooperação e a partilha de saberes, o desenvolvimento das capacidades de observação, previsão, experimentação e registro, o desenvolvimento do gosto pela preservação da memória coletiva. As atividades práticas desenvolvidas revelaram-se propiciadoras da triangulação ciência-criança-patrimônio sociocultural, ao criarem o contexto para estas crianças "reciclarem recordações por meio da magia das Ciências", isto é, descobriram o meio sociocultural da família/meio trilhando os caminhos da experiencia em Ciências e desta forma, descobriram segredos do passado. As crianças ao terem a oportunidade para expressarem as suas concepções, apresentarem soluções/explicações/conclusões, juízos de valor, aprenderam a fazer opções em relação a situações reais, vindas do meio ao qual se integram. Estes percursos de aprendizagem despertaram, na criança, a curiosidade e o desejo de descobrir e aprender sobre o mundo que a rodeia e a cultura emque se insere, desenvolvendo-lhe o sentido da preservação dos valores culturais da sua família/comunidade.

\section{Referências}

ALMEIDA, António; VILELA, Mário C. Didáctica das ciências: aceleração cognitiva - teoria e prática. Rio Tinto: Edições ASA, 1996.

BARBIER, Jean Marie. Elaboração de projectos de acção e planificação. Porto: Porto Editora, 1996.

BENTO, António Maria Veloso. Articulação da educação formal e não formal. Educare/ Educere, 20, p. 25-35, 2007.

CACHAPUZ, António. Ensino das ciências e mudança conceptual: estratégias inovadoras de formação de professores - em inovação. Lisboa: Instituto de Inovação Educacional, 1993. p. 47-54. Vol. 3.

Questões e razões: melhorar o ensino das ciências. Noesis, p. 26-29, jul./set. 2009. 
CACHAPUZ, António; PRAIA, João; JORGE, Manuela. Ciência, educação em ciência e ensino das ciências. 1. ed. Lisboa: Ministério da Educação, 2002.

CARVALHO, A. D. et al. A construção do projecto de escola. Porto: Porto Editora, 1993. CARVALHO, Angelina; DIOGO, Fernando. Projecto educativo. Porto: Edições Afrontamento, 1994.

CONSELHO NACIONAL DE EDUCAÇÃO. Ensino experimental e construção de saberes. Lisboa: Ministério da Educação, 1999.

COLE, Michael. Psicologia cultural. Madrid: Morata, 1999.

COSTA, António et al. 1st Cycle of Basic Education Teachers and their Engagement in Science and Technology. Asian Journal of Education and e-Learning, vol. 2, Issue 3, 2014. ISSN: 2321-2454.

COSTA, Jorge Adelino. Gestão escolar - participação, autonomia, projecto educativo da escola. 1. ed. Lisboa: Texto Editora, 1991.

ESHACH, Haim Science Literacy in Primary Schools and Pre-schools. Dordrecht: Springer, 2006.

FERREIRA, Maria Eduarda; PORTEIRO, Ana Claudia; PITARMA, Rui. Enhancing Children's Success in Science Learning: An Experience of Science Teaching in Teacher Primary School Training. Journal of Education and Practice, 6, 8, p. 24-31, 2015.

FERREIRA, Maria Eduarda; CRUZ, Catarina; PITARMA, Rui Teaching ecology to children of preschool education to instill environmentally friendly behaviour. International Journal of Environmental \& Science Education, 11, 12, p. 5.619-5.632, 2016.

FORMOSINHO, Júlia Oliveira (Org.). Modelos curriculares para a educação de infância - construindo uma práxis de participação. Porto: Porto Editora, 2013.

GAUER, Gustavo; GOMES, William Barbosa. Recordação de eventos pessoais: memória autobiográfica, consciência e julgamento. Psicologia: Teoria e Pesquisa, 24(4), p. 507-514, 2008.

HOHMANN, Mary. Educar a criança. Lisboa: Fundação Calouste Gulbenkian, 1997.

KANT, Immanuel. Crítica da razão pura. Lisboa: Fundação Calouste Gulbenkian, 1985.

KATZ, Lilian; CHARD, Sylvia. A abordagem de projecto na educação de infância. Lisboa: Fundação Calouste Gulbenkian, 1997.

LOURENÇO, Abílio Afonso; PAIVA, Maria Olímpia A. A motivação escolar e o processo de aprendizagem. Ciência \& Cognição, 15(2), p. 131-141, 2010.

MARCOZZI, Alayde; DORNELLES, Leny; REGO, Marion Vilas Boas Sá. Ensinando a criança: um guia para o professor primário. Rio de Janeiro: Ao Livro Técnico, 1980. 
MARQUES, R. Valores éticos e cidadania na escola. Lisboa: Presença, 2001.

MARTINS, Isabel P.; VEIGA, M. L. Uma análise do currículo da escolaridade básica na perspectiva da educação em ciências. 1. ed. Coimbra: Instituto de Inovação Educacional, 1999.

MARTINS, Martins P. et al. Educação em ciências e ensino experimental. 2. ed. Lisboa: Ministério da Educação - DGIDC, 2007.

. Despertar para a ciência: actividades dos 3 aos 6. 1. ed. Lisboa: Ministério da Educação - DGIDC, 2009.

MATEUS, Maria Esteves. Metodologias de trabalho de projecto: Nova relação entre os saberes escolares e os saberes sociais. Eduser: Revista de Educação-Prática Pedagógica. 3(2), p. 3-15, 2011.

MENDONÇA, Marília. Ensinar e aprender por projectos. Porto: Edições ASA, 2002. MINISTÉRIO DA EDUCAÇÃO. Orientações curriculares para a educação pré-escolar em Portugal. Lisboa: Ministério da Educação, 1997.

. Orientações curriculares para a educação pré-escolar. 3. edi. Lisboa: Direcção-Geral de Inovação e de Desenvolvimento Curricular, 2007.

MUNDOS DE VIDA. O segredo dos sabonetes. In: MUNDOS DE VIDA (Ed.). Dia Nacional do Pijama. Lousado, Portugal, 2013.

PEREIRA, Alda. Educação para a ciência. Lisboa: Universidade Aberta, 2002.

PEREIRA, Mariana Pereira (Coord.). Didáctica das ciências da natureza. Lisboa: Universidade Aberta, 1992.

POZO, Juan Ignacio; GOMEZ CRESPO, Miguel Angel. Aprender y ensinar ciência. Del conocimiento cotidiano al conocimiento científico. Madrid: Ediciones Morata, 2001.

REIS, Carlos (Coord.). Programas de português do ensino básico. Lisboa: Ministério da Educação, 2009. Correcto

SÁ, Joaquim. A abordagem experimental das ciências no jardim de infância e $1^{\circ}$ ciclo do ensino básico: sua relevância para o processo de educação científica nos níveis de escolaridade seguintes. Lisboa: Universidade Aberta, 2000.

Renovar as práticas no $1^{o}$ ciclo pela via das ciências da natureza. Porto: Porto Editora, 2002.

SÁ, Joaquim; VARELA, Paulo. Das Ciências experimentais à literacia. Porto: Porto Editora, 2007.

SANTOS, Eduarda et al. (Ed.). Ensino das ciências. 1. ed. Mem Martins: Ministério da Educação - Instituto de Inovação Educacional, 1997. 
SANTOS, Milice Ribeiro; LEITE, Elvira; MALPIQUE, Manuela. Trabalho de Projecto - II. Leituras comentadas. 3. ed. Porto: Edições Afrontamento, 2008.

VASCONCELOS, Teresa. Trabalho por projeto "Pedagogia de Fronteira". Da Investigação às Práticas, I (3), p. 8-30, 2011 a.

(Coord.) Trabalho por projectos na educação de infância: mapear aprendizagens, integrar metodologias. Lisboa: Ministério da Educação e Ciência - DGIDC, 2011 b.

WEIKART, David P. Early childhood education: need and opportunity. Paris: Unesco, 2000. (Published in the séries: Fundamentals of educational Planning, 65).

WILLIAMS, Robert A.; ROCKWELL, Robert E.; SHERWOOD, Elizabeth A. Ciência para crianças. 2. ed. Lisboa: Instituto Piaget, 2003.

Recebido em: 31/3/2016

Aceito em: 4/11/2016 